\title{
JANVIER-FÉVRIER 1986
}

\section{8• ANNÉE - N० 757}

\section{revue internationale de la croix-rouge}

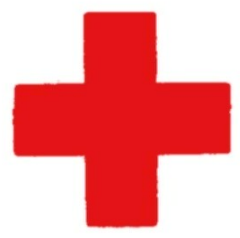

INTER ARMA CARITAS

GENÈVE

COMITÉ INTERNATIONAL DE LA CROIX-ROUGE FONDÉ EN 1863 


\title{
COMITÉ INTERNATIONAL DE LA CROIX-ROUGE
}

M. ALEXANDRE HAY, avocat, ancien directeur général de la Banque nationale suisse, président (membre depuis 1975)

$\mathrm{M}^{\text {me }}$ DENISE BINDSCHEDLER-ROBERT, docteur en droit, professeur à l'Institut universitaire de hautes études internationales, Genève, juge à la Cour européenne des droits de l'homme, vice-présidente (1967)

MM. MAURICE AUBERT, docteur en droit, vice-président (1979)

JACQUES F. DE ROUGEMONT, docteur en médecine (1967)

ULRICH MIDDENDORP, docteur en médecine, chef de la clinique chirurgicale de l'Hôpital cantonal, Winterthour (1973)

HENRY HUGUENIN, banquier (1974)

RICHARD PESTALOZZI, docteur en droit, ancien vice-président du CICR (1977)

ATHOS GALLINO, docteur en médecine, maire de Bellinzone (1977)

ROBERT KOHLER, docteur ès sciences économiques (1977)

RUDOLF JÄCKLI, docteur ès sciences (1979)

DIETRICH SCHINDLER, docteur en droit, professeur à l'Université de Zurich (1961$1973 ; 1980)$

HANS HAUG, docteur en droit, professeur à l'Ecole des hautes études économiques et sociales de Saint-Gall, ancien président de la Croix-Rouge suisse (1983)

PETER A R BENZ, licencié ès sciences politiques, conseiller municipal de Winterthour (1983)

PIERRE KELLER, docteur en philosophie en relations internationales (YALE), banquier (1984)

RAYMOND R. PROBST, docteur en droit, ancien ambassadeur de Suisse, ancien secrétaire d'Etat au Département fédéral des Affaires étrangères à Berne (1984)

ODILO GUNTERN, docteur en droit, ancien député au Conseil des Etats (1985)

ANDRÉ GHELFI, secrétaire central et vice-président de la Fédération suisse des travailleurs de la métallurgie (1985)

\section{CONSEIL EXÉCUTIF}

\author{
M. ALEXANDRE HAY, président \\ M. MAURICE AUBERT \\ M. RICHARD PESTALOZZI \\ M. ATHOS GALLINO \\ M. RUDOLF JÄCKLI \\ M. PIERRE KELLER
}

Le Comité international de la Croix-Rouge (CICR) est, avec la Ligue des Sociétés de la Croix-Rouge et du Croissant-Rouge et les 137 Sociétés nationales de la Croix-Rouge et du Croissant-Rouge reconnues, l'une des trois composantes de la Croix-Rouge internationale.

Institution humanitaire indépendante, le CICR est l'organe fondateur de la Croix-Rouge. Intermédiaire neutre en cas de conflits armés et de troubles, il s'efforce d'assurer, de sa propre initiative ou en se fondant sur les Conventions de Genève, protection et assistance aux victimes des guerres internationales et civiles, des troubles et tensions internes, apportant ainsi sa contribution à la paix dans le monde. 


\section{REVUE INTERNATIONALE DE LA CROIX-ROUGE}

ISSN 0035-3361

\section{SOMMAIRE}

COMITE INTERNATIONAL

DE LA CROIX-ROUGE

FAITS ET DOCUMENTS

LIVRES ET REVUES
JANVIER-FÉVRIER 1986 - No 757

IV ${ }^{\mathrm{e}}$ session de l'Assemblée générale de la Ligue $\quad 3$

Conseil des Délégués $1985 \ldots \ldots$. . . . . 9

Résolution et Décisions du Conseil des Délégués $1985 \ldots \ldots \ldots$. . . . . . . .

André Durand: L'évolution de l'idée de paix dans la pensée d'Henry Dunant . . . . . . 16

Missions du président du CICR . . . . . . 52

Mission en Espagne d'un membre du CICR . $\quad 53$

Un délégué du CICR trouve la mort en Angola 54

Adhésion de la République fédérale islamique des Comores aux Conventions de Genève et aux Protocoles. . . . . . . . . . . 54

Le Saint-Siège ratifie les Protocoles . . . . . 55

Déclaration du Saint-Siège . . . . . . . . 55

Adhésion de la République orientale de l'Uruguay aux Protocoles ........... . 57

Adhésion de la République du Suriname aux Protocoles ............... 57

Activités extérieures:

Afrique - Amérique latine - Asie/Pacifique - Moyen-Orient . . . . . . . . . 58

Etats parties aux Conventions de Genève et aux Protocoles additionnels (31.12.1985) . .

H. S. Levie: Protection of War Victims, Supplement . . . . . . . . . 76 
La Revue internationale de la Croix-Rouge est publiée par le Comité international de la Croix-Rouge (CICR) depuis 1869. Elle a porté à l'origine le titre de «Bulletin international des Sociétés de secours aux militaires blessés», puis de "Bulletin international des Sociétés de la Croix-Rouge».

- Organe officiel du CICR et de la Croix-Rouge internationale,

- publication spécialisée dans le droit international humanitaire et la doctrine du CICR,

- chronique des activités internationales de la Croix-Rouge, ouvrage de référence essentiellement, qui garde la mémoire des événements,

la Revue internationale maintient un courant d'informations et constitue le lien nécessaire entre les membres de la Croix-Rouge internationale.

La Revue internationale de la Croix-Rouge paraît, une fois tous les deux mois, en trois éditions principales:

en français: Revue inTernationale de la Croix-Rouge

en anglais: INTERnational Review of THE ReD Cross (depuis 1961)

en espagnol: Revista Internacional de la Cruz Roja (depuis 1976)

Elle publie également, en allemand, un cahier d'Extraits des textes parus dans les éditions principales.

RÉDACTION: Michel Testuz

ADRESSE: $\quad$ Revue internationale de la Croix-Rouge

17, avenue de la Paix

$\mathrm{CH}$ - 1202 - Genève, Suisse

ABONNEMENTS: un an 30 francs suisses; le numéro 5 francs.

Extraits en allemand: un an 10 francs; le numéro 2 francs.

Compte de chèques postaux: 12 - 1767 Genève

Compte bancaire: 129.986 Société de Banque Suisse, Genève

Seuls les textes signés par le Comité international de la Croix-Rouge engagent la responsabilité de celui-ci. 